\title{
Alteration in Integrated Relaxation Pressure During Successive Swallows in Subjects With Normal Manometry Versus Those With Esophagogastric Junction Outflow Obstruction
}

\author{
Abbinaya Elangovan, Fahmi Shibli, and Ronnie Fass* \\ The Esophageal and Swallowing Center, Division of Gastroenterology and Hepatology, MetroHealth Medical Center, Case Western Reserve \\ University, Cleveland, OH, USA
}

\section{Background/Aims}

Integrated relaxation pressure (IRP) is defined as the average minimum esophagogastric junction pressure for 4 seconds of relaxation (contiguous or noncontiguous) within 10 seconds of swallowing. The durability of IRP values during successive swallows in the supine position remains to be elucidated. The aim is to determine alteration in IRP values during successive swallows among subjects with normal esophageal manometry versus those with esophagogastric junction outflow obstruction (EGJOO).

\section{Methods}

Consecutive subjects, who underwent high-resolution esophageal manometry (HREM) were included in the study. Individuals had to have either normal manometry or EGJOO. A total of 10 wet swallows of $5 \mathrm{~mL}$ water were performed after an adaptation period of a minimum of 3 minutes. Mean IRP was analyzed for both subject groups for each individual swallow.

\section{Results}

Thirty-one patients with EGJOO and seventy patients with normal manometry were included. As expected, the median IRP was higher in EGJOO patients compared to those with normal HREM (mean: 23.92 vs $5.34, P<0.001$ ). The mean IRP of the last swallow was $40 \%$ lower than the mean IRP of the first swallow in the normal subjects $(P=0.015)$. In contrast, the difference in the mean IRP value in the EGJOO group between the first and the last swallow was $19 \%(P=0.018)$.

\section{Conclusions}

This study demonstrated that there is a significant decline in the mean IRP during successive swallows in subjects with normal esophageal manometry and those with EGJOO, despite adequate adaptation periods. This decline in IRP was less pronounced in EGJOO.

(J Neurogastroenterol Motil 2021;27:185-190)

Key Words

Deglutition; Deglutition disorders; Esophageal sphincter, lower; Esophagogastric junction; Manometry

\section{Received: June 18, 2020 Revised: October 30, 2020 Accepted: October 30, 2020}

(a) This is an Open Access article distributed under the terms of the Creative Commons Attribution Non-Commercial License (http://creativecommons. org/licenses/by-nc/4.0) which permits unrestricted non-commercial use, distribution, and reproduction in any medium, provided the original work is properly cited.

*Correspondence: Ronnie Fass, MD, FACG

The Esophageal and Swallowing Center, Division of Gastroenterology and Hepatology, MetroHealth Medical Center, Case Western Reserve University, 2500 MetroHealth Dr, Cleveland, OH 44109, USA Tel: +1-216-778-3145, Fax: +1-216-778-2074,E-mail: Ronnie.fass@gmail.com 


\section{Introduction}

High-resolution esophageal manometry (HREM) is currently the most widely utilized technique to evaluate patients with dysphagia after mechanical obstruction and mucosal disease are ruled out during endoscopy. ${ }^{1}$ The technique evaluates the dynamic action of the upper esophageal sphincter, the segmental character of esophageal peristalsis, and the complex functional anatomy of the esophagogastric junction. ${ }^{1}$ It provides spatiotemporal plots and gives real-time measurement of intraluminal pressures of esophageal contractions as well as resting and relaxation pressures of the lower esophageal sphincter (LES). ${ }^{2}$ Hence it has a high sensitivity to diagnose disorders of esophageal motility. ${ }^{2}$

The manometric values from the HREM are interpreted by the Chicago classification version 3.0 (v3.0) which is based on the normative data of ten 5 -mL swallows performed in the supine position. ${ }^{3}$ Integrated relaxation pressure (IRP), a measure of esophagogastric junction relaxation, is an important metric of HREM ${ }^{4}$ IRP corresponds to the mean pressure of 4 seconds of the greatest post deglutitive relaxation in a 10-second gap at the beginning of a swallow. ${ }^{5}$ It compensates for the diaphragmatic contraction during LES relaxation as well as eliminates the pseudo-relaxation due to movement artifacts. ${ }^{5}$ IRP $>15 \mathrm{mmHg}$ (95th percentile) is considered abnormal. ${ }^{3}$

While the positional variation of IRP values has been demonstrated in multiple studies, the durability of IRP during successive swallows in the same position is not well established. Hence, we aimed to determine the durability of the recorded IRP values during successive swallows in subjects with normal HREM versus those with esophagogastric junction outflow obstruction (EGJOO). Our hypothesis was that there should not be a significant difference within each group from the first to the last swallow but there should be a significant difference between the groups.

\section{Materials and Methods}

\section{Study Population}

Consecutive patients who underwent HREM were evaluated for this study. Only subjects with normal esophageal manometry or EGJOO were assessed. Exclusion criteria included upper gut surgery such as bariatric or anti-reflux, presence of esophageal anatomical abnormalities such as stricture, ring, ulceration, biopsy proven infection, benign and malignant tumors, and eosinophilic esophagitis. Furthermore, subjects with medical diagnoses such as systemic sclerosis, systemic lupus erythematosus, pemphigus vulgaris, pemphigoid conditions, lichen planus, rheumatoid arthritis, hypothyroidism, hyperthyroidism, diabetes mellitus, amyloidosis, Plummer Vinson syndrome, and multiple sclerosis were also excluded. In addition, patients using medications such as nitrates, beta blockers, calcium channel blockers, anticholinergics, tricyclic anti-depressants, benzodiazepines, opioids, and prokinetics that can affect esophageal function were excluded as well. Demographic characteristics such as age, sex, ethnicity, race, body mass index, smoking, alcohol, medical, surgical, endoscopic, and medication history were collected. The study was approved by the MetroHealth Institutional Review Board (IRB19-00541).

\section{High-resolution Esophageal Manometry Procedure}

HREM was performed using a solid-state system (Laborie Medical Technologies, Quebec City, Canada) with 36 circumferential pressure sensors spaced at $1-\mathrm{cm}$ interval with a diameter of $5.3 \mathrm{~mm}$. Patients were required to fast after midnight on the night prior to the test. During the procedure, the manometry probe was placed transnasally and positioned in the stomach to span the entire length of the esophagus from the hypopharynx to the stomach with approximately 5 intra-gastric sensors. The patients were placed in the supine position with a minimum adaptation period of 3 minutes. After at least 3 deep inspirations during a 30 -second baseline period, the patients were asked to swallow $5 \mathrm{~mL}$ of water at room temperature about 10 times at an interval of 30 seconds. The pressure data tracings were quantitatively analyzed using dedicated computerized HREM acquisition, display, and analysis Medical Measurement Systems software (File version; 9.1.11.0; Laborie Medical Technologies, Quebec City, Canada) to derive color-encoded pressure topography plots called esophageal pressure tracings and pressure metrics.

\section{Data Analysis}

HREM plots were analyzed according to the hierarchical algorithm of Chicago classification v3.0. Subjects with a normal HREM or EGJOO were included in the study. EGJOO was defined according to the Chicago classification v3.0 as an elevated median IRP ( > $18 \mathrm{mmHg}$ ) with evidence of esophageal peristalsis such that the criteria of achalasia were not met. ${ }^{3}$ As recommended, the median IRP was utilized instead of mean IRP to decrease the effect of outliers in the interpretation of the results. ${ }^{3}$ The mean of the median IRPs as well as the mean of parameters determining esophageal contractile function such as distal contractile integral 
Table 1. Demographics of Subjects With Normal High-resolution Esophageal Manometry and Patients With Esophagogastric Junction Outflow Obstruction

\begin{tabular}{|c|c|c|c|c|}
\hline Variable & $\begin{array}{l}\text { Normal manometry } \\
\qquad(\mathrm{n}=70)\end{array}$ & $\begin{array}{l}\text { EGJOO } \\
(n=31)\end{array}$ & Chi-square & $P$-value \\
\hline Male & $29(41.4)$ & $5(16.1)$ & 5.93 & 0.015 \\
\hline \multicolumn{5}{|l|}{ Ethnicity/Race } \\
\hline Non-Hispanic White & $42(60.0)$ & $17(54.8)$ & 0.24 & 0.627 \\
\hline Non-Hispanic Black & $17(24.3)$ & $12(38.7)$ & 2.19 & 0.139 \\
\hline Hispanic & $5(7.1)$ & $1(3.2)$ & 0.58 & 0.445 \\
\hline Smoking & $38(54.3)$ & $19(61.3)$ & 0.46 & 0.497 \\
\hline \multirow[t]{2}{*}{ Alcohol } & $26(37.1)$ & $16(51.6)$ & 1.87 & 0.172 \\
\hline & & & $t$ value & \\
\hline Age (yr) & $55.10 \pm 12.60$ & $55.84 \pm 13.20$ & -0.37 & 0.713 \\
\hline $\mathrm{BMI}$ & $30.34 \pm 8.50$ & $35.35 \pm 11.80$ & -2.09 & 0.043 \\
\hline Median IRP & $5.34 \pm 4.40$ & $23.92 \pm 6.70$ & -13.59 & $<0.001$ \\
\hline $\mathrm{CFV}$ & $4.20 \pm 2.10$ & $4.37 \pm 2.50$ & -0.33 & 0.727 \\
\hline DCI & $1470.75 \pm 921.50$ & $1719.36 \pm 1431.30$ & -0.89 & 0.296 \\
\hline DL & $7.15 \pm 1.30$ & $10.61 \pm 17.40$ & -1.11 & 0.278 \\
\hline
\end{tabular}

HREM, high-resolution esophageal manometry; EGJOO, esophagogastric junction outflow obstruction; BMI, body mass index; IRP, integrated relaxation pressure; CFV, contractile front velocity; DCI, distal contractile integral; DL, distal latency.

Values are presented as $\mathrm{n}(\%)$ or mean $\pm \mathrm{SD}$.

(DCI), contractile front velocity (CFV), and distal latency (DL) were compared between both groups.

In each group, the mean IRP of each swallow from 1 to 10 was evaluated and compared to the first or previous swallow value. IRP was measured only during the supine position, so a comparison between those with normal manometry and those with EGJOO could be made. Subgroup analyses were also made between individuals presenting with gastroesophageal reflux disease (GERD) and dysphagia in either group.

\section{Statistical Methods}

Demographics, clinical and manometric characteristics of subjects with normal manometry were compared to those with EGJOO. Categorical data were analyzed using the chi-square test and continuous data was analyzed using the Student $t$ test in Microsoft Excel 2016. A $P$-value $<0.05$ was considered statistically significant. Intraclass coefficient estimates and their $95 \%$ confidence intervals were calculated using IBM SPSS Statistics version 26 (IBM Corporation, Armonk, NY). A two-way mixed-effect model with Crohnbach's alpha was used to assess the intra-rater reliability based on single rating and consistency. The test was interpreted as follows: $<0.50$, poor; between 0.50 and 0.75 , fair; between 0.75 and 0.90 , good; and above 0.90 , excellent. ${ }^{6}$
Table 2. Indication for High-resolution Esophageal Manometry for Those With Normal Test and Patients Diagnosed With Esophagogastric Junction Outflow Obstruction

\begin{tabular}{lcccc}
\hline \multicolumn{1}{c}{ Indication } & $\begin{array}{c}\text { Normal } \\
\text { manometry } \\
(\mathrm{n}=70)\end{array}$ & $\begin{array}{c}\text { EGJOO } \\
(\mathrm{n}=31)\end{array}$ & $\begin{array}{c}\text { Chi- } \\
\text { square }\end{array}$ & $P$-value \\
\hline Dysphagia & $46(65.7 \%)$ & $21(67.7 \%)$ & 0.04 & 0.845 \\
GERD & $17(24.3 \%)$ & $7(22.6 \%)$ & 0.04 & 0.845 \\
NCCP & $8(11.4 \%)$ & $4(12.9 \%)$ & 0.05 & 0.831 \\
Globus & $11(15.7 \%)$ & $2(6.5 \%)$ & 1.61 & 0.205 \\
Cough/Hoarseness & $1(1.4 \%)$ & $1(3.2 \%)$ & 0.36 & 0.549 \\
Dyspepsia/ & $1(1.4 \%)$ & $1(3.2 \%)$ & 0.36 & 0.549 \\
$\quad$ Belching/Nausea & & & & \\
Before bariatric & $0(0.0 \%)$ & $3(9.7 \%)$ & NA & NA \\
surgery & & & & \\
\hline
\end{tabular}

EGJOO, esophagogastric junction outflow obstruction; HREM, high-resolution esophageal manometry; GERD, gastroesophageal reflux disease; NCCP, noncardiac chest pain; NA, not applicable.

\section{Results}

A total of 70 subjects with normal HREM and 31 patients with EGJOO were included in the study. The demographic and manometric characteristics of either group are depicted in Table 1. EGJOO demonstrated a higher proportion of women compared to those with normal manometry $(P=0.015)$. The mean age group was around 55 years of age for both groups. The body mass index 
Table 3. Mean Integrated Relaxation Pressure and Percentage Change of Mean Compared to the First Swallow in Subjects With Normal Highresolution Esophageal Manometry and those With Esophagogastric Junction Outflow Obstruction

\begin{tabular}{|c|c|c|c|c|c|c|}
\hline \multirow[b]{2}{*}{ Swallow } & \multicolumn{3}{|c|}{ Normal manometry } & \multicolumn{3}{|c|}{ EGJOO } \\
\hline & Mean (mmHg) & SEM & $\begin{array}{l}\text { Percentage change of } \\
\text { mean compared to } \\
\text { the first swallow }\end{array}$ & Mean (mmHg) & SEM & $\begin{array}{l}\text { Percentage change of } \\
\text { mean compared to } \\
\text { the first swallow }\end{array}$ \\
\hline Swallow 1 & 8.84 & 0.94 & & 25.84 & 1.67 & \\
\hline Swallow 2 & 7.13 & 0.70 & $-19.34 \%$ & 25.08 & 1.74 & $-2.93 \%$ \\
\hline Swallow 3 & 7.4 & 0.70 & $-16.29 \%$ & 23.76 & 1.04 & $-8.05 \%$ \\
\hline Swallow 4 & 5.87 & 0.60 & $-33.60 \%$ & 26.39 & 1.51 & $2.12 \%$ \\
\hline Swallow 5 & 5.60 & 0.63 & $-36.65 \%$ & 23.63 & 1.60 & $-8.55 \%$ \\
\hline Swallow 6 & 5.56 & 0.56 & $-37.10 \%$ & 25.27 & 1.96 & $-2.18 \%$ \\
\hline Swallow 7 & 4.31 & 0.53 & $-51.24 \%$ & 23.40 & 1.63 & $-9.43 \%$ \\
\hline Swallow 8 & 4.41 & 0.52 & $-50.11 \%$ & 21.69 & 1.62 & $-16.04 \%$ \\
\hline Swallow 9 & 5.33 & 0.59 & $-65.85 \%$ & 22.26 & 1.42 & $-13.86 \%$ \\
\hline Swallow 10 & 5.29 & 0.68 & $-40.15 \%$ & 20.95 & 1.56 & $-18.91 \%$ \\
\hline Mean change & & & $-38.93 \%$ & & & $-8.65 \%$ \\
\hline
\end{tabular}

EGJOO, esophagogastric junction outflow obstruction; SEM, standard error of mean.

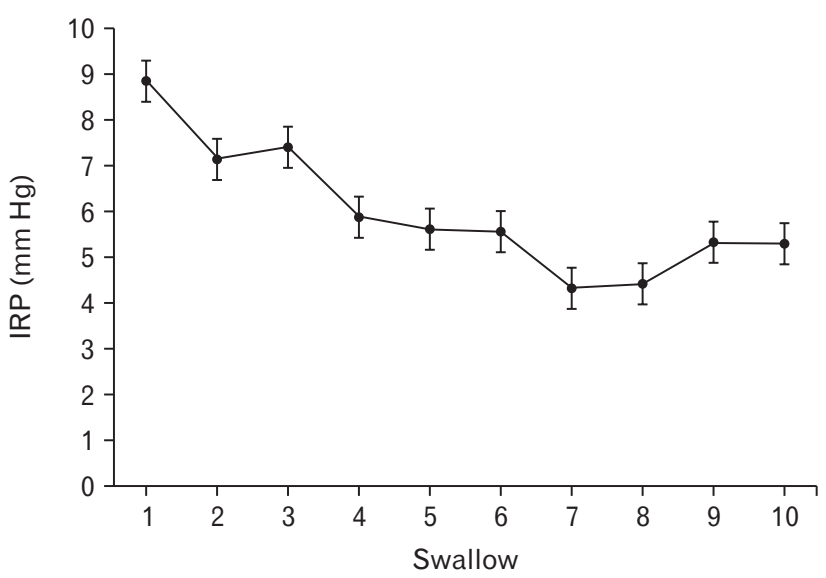

Bars indicate standard error of mean

Figure 1. Mean integrated relaxation pressure (IRP) of individual swallows in subjects with normal manometry $(\mathrm{mmHg})$.

of EGJOO group was significantly higher $(P=0.043)$. No significant difference was observed between the 2 groups with regards to other demographic variables. As expected, the median IRP was higher in patients with EGJOO compared to subjects with normal HREM (23.92 vs 5.34, $P<0.001$ ). There were no significant differences in the mean CFV, DCI, and DL between subjects with normal HREM and patients with EGJOO (4.20 vs 4.37, $P=$ $0.727 ; 1470.75$ vs $1719.36, P=0.296 ; 7.15$ vs $10.61, P=0.278$, respectively).

The most common clinical indication for HREM in either group was dysphagia followed by GERD, non-cardiac chest pain,

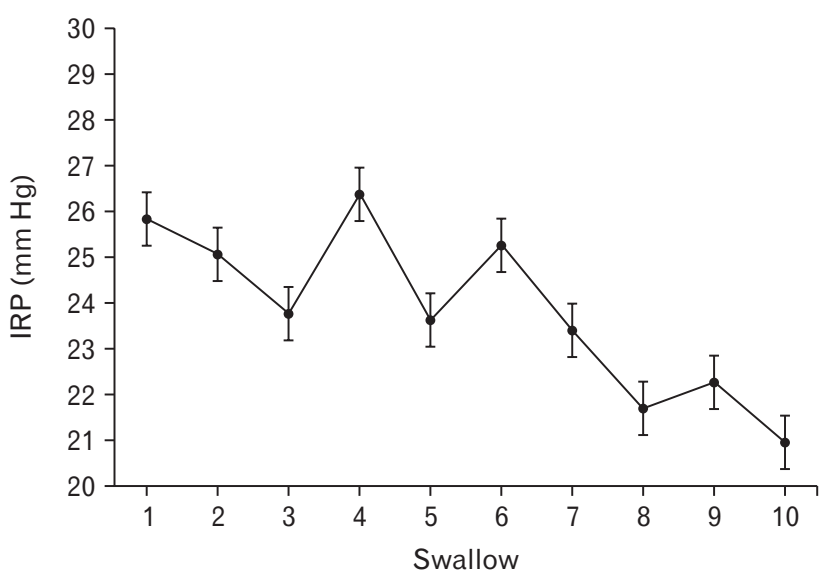

Bars indicate standard error of mean

Figure 2. Mean integrated relaxation pressure (IRP) of individual swallows of subjects with esophagogastric junction outflow obstruction $(\mathrm{mmHg})$.

and globus sensation. There was no significant difference between the 2 groups with regards to the indication of HREM (Table 2).

In subjects with normal HREM, the mean IRP of the tenth swallow was $40 \%$ lower than the mean IRP of the first swallow (8.84 vs $5.29, P=0.015$ ) (Table 3 ). In patients with EGJOO, the mean IRP of the tenth swallow was $19 \%$ lower than the mean IRP of the first swallow (25.84 vs 20.95, $P=0.018$ ). Figures 1 and 2 depict the decline observed in the mean IRP between successive swallows which were recorded in both study groups. The mean of the difference between the first and the last swallow was not significantly 
Table 4. Mean Distal Contractile Integral and Percentage Change of Mean Compared to the First Swallow in Subjects With Normal Highresolution Esophageal Manometry and Those With Esophagogastric Junction Outflow Obstruction

\begin{tabular}{|c|c|c|c|c|c|c|}
\hline \multirow[b]{2}{*}{ Swallow } & \multicolumn{3}{|c|}{ Normal manometry } & \multicolumn{3}{|c|}{ EGJOO } \\
\hline & Mean (mmHg) & SEM & $\begin{array}{l}\text { Percentage change of } \\
\text { mean compared to } \\
\text { the first swallow }\end{array}$ & Mean (mmHg) & SEM & $\begin{array}{l}\text { Percentage change of } \\
\text { mean compared to } \\
\text { the first swallow }\end{array}$ \\
\hline Swallow 1 & 1734.87 & 145.50 & & 1335.42 & 266.58 & \\
\hline Swallow 2 & 1353.54 & 112.59 & $-21.98 \%$ & 1875.10 & 776.66 & $40.41 \%$ \\
\hline Swallow 3 & 1355.63 & 112.89 & $-21.86 \%$ & 1826.00 & 515.97 & $36.74 \%$ \\
\hline Swallow 4 & 1345.91 & 131.92 & $-22.42 \%$ & 1566.06 & 667.41 & $17.27 \%$ \\
\hline Swallow 5 & 1507.57 & 155.97 & $-13.10 \%$ & 1413.07 & 359.19 & $5.81 \%$ \\
\hline Swallow 6 & 1390.66 & 133.11 & $-19.84 \%$ & 1913.20 & 565.62 & $43.27 \%$ \\
\hline Swallow 7 & 1446.44 & 122.69 & $-16.63 \%$ & 1432.23 & 449.46 & $7.25 \%$ \\
\hline Swallow 8 & 1458.60 & 141.73 & $-15.92 \%$ & 1686.42 & 451.63 & $26.28 \%$ \\
\hline Swallow 9 & 1325.40 & 104.12 & $-23.60 \%$ & 2264.87 & 679.66 & $69.60 \%$ \\
\hline Swallow 10 & 1535.11 & 153.70 & $-11.51 \%$ & 1960.03 & 672.64 & $46.77 \%$ \\
\hline Mean change & & & $-18.54 \%$ & & & $32.60 \%$ \\
\hline
\end{tabular}

EGJOO, esophagogastric junction outflow obstruction; SEM, standard error of mean.

different between those with normal HREM and EGJOO (3.55 vs $4.89, P=0.513)$. Table 3 summarizes the changes in IRP values during successive swallows in both study groups. The intraclass coefficient for intra-rater reliability was between good and excellent (0.91; 95\% confidence interval, 0.81-0.97) for normal manometry. The intraclass coefficient for intra-rater reliability was between fair and good (0.62; 95\% confidence interval, 0.19-0.89) for EGJOO.

Analysis of DCI showed no statistical difference between the mean DCI of the first and tenth swallow in subjects with normal HREM (1734.87 vs $1535.11, P=0.349)$ and subjects with EGJOO (1335.42 vs 1960.03, $P=0.142$ ) (Table 4).

Subgroup analyses indicated that among subjects with normal HREM, the decline in IRP between the first and last swallow was not significantly different between subjects with GERD (47\%) and those with dysphagia (41\%) (mean $4.13 \pm 6.30$ vs $4.82 \pm 7.36, P$ $=0.743)$. Similarly, there was no significant difference in the decline in IRP between GERD (15\%) and dysphagia (17\%) in patients with EGJOO (mean $3.57 \pm 11.08$ vs $3.88 \pm 10.44, P=0.947$ ).

\section{Discussion}

All versions of the Chicago classification placed the IRP at the beginning of the hierarchical analysis emphasizing the importance of this metric in immediately identifying disorders like achalasia and EGJOO., Consequently, obtaining an accurate value of the IRP is pivotal to the interpretation of HREM. In this study, we were able to show that despite following the current HREM performance guide- lines, successive swallows have been associated with almost a predictable decline in the IRP between the first and the last swallow while the patient is in the supine position. This was noted in both subjects with normal esophageal manometry and those with EGJOO.

While it is acceptable that there would be variations in the measured IRP values among the swallows, the study shows a steady decline from the first to the tenth swallow that is accentuated in subjects with normal HREM. A similar phenomenon was observed in patients with EGJOO but to a lesser extent. The main mechanism behind the decline in IRP from the first to the last swallow is unknown but we hypothesize that it could be due to the longer adaptation of the LES to the catheter or possibly repositioning or migration of the catheter that may occur with each swallow.

Among those with normal esophageal manometry, the decline in IRP was demonstrated in individuals with dysphagia (41\%) and those with GERD (47\%). It is also notable that the mean of the median IRP of those with dysphagia $(6.02 \mathrm{mmHg})$ was higher than those with GERD (4.48 $\mathrm{mmHg}$ ). Overall, the difference in the percentage decline was relatively small. In addition, a higher LES resting pressure and higher intrabolus pressure can be seen in patients with dysphagia and normal IRP. ${ }^{8}$ Similarly, the fall in IRP was lower in EGJOO compared to subjects with normal manometry. This could likely reflect the inherent anatomical or functional abnormalities in patients with EGJOO resulting in elevated IRP value.

Multiple studies have demonstrated IRP changes in the upright position. In the upright position, under the effect of gravity, 
there is a decrease in $\mathrm{DCI}^{9-12}$ and $\mathrm{DL}^{9}$ with an increase in $\mathrm{CFV}^{12}$ As a consequence of the above, the median IRP decreases ${ }^{10,13}$ due to the concomitant reduction in intrabolus pressure ${ }^{10}$ as the IRP is the sum of the LES pressure, crural diaphragm and intrabolus pressure. ${ }^{14}$ Furthermore, Sweis at al ${ }^{12}$ demonstrated an increase in IRP when solid boluses were used instead of liquids. However, another recent study by Xiang et al ${ }^{15}$ did not show significant changes in the median IRP between solid and liquid boluses. While a significant number of studies have compared differences between upright vs supine positions and solid vs liquid boluses, to our knowledge, no other studies thus far described changes in IRP among successive swallows in a standardized procedure using water boluses in the supine position.

Our study has a few limitations. It would have been helpful to have in the EGJOO group IRP measurements in the upright position as well. However, this is still not considered a routine part of standard HREM. Thus, this study adds to the existing literature on studies with HREM performed in the supine position. Furthermore, it would have been helpful to assess a larger number of subjects in each group and possibly add other centers to perform HREM in order to exclude local procedure performance issues or equipment-related shortcomings.

Our study suggests that current calculations of the IRP value should take into consideration the decline in IRP value from the first to the last swallow. It is possible that instead of the median, the average of the first and last swallow would better represent the true value of the IRP.

In conclusion, there is a significant decline in the IRP value from the first to the last swallow in subjects with normal HREM. This difference was less prominent but appreciable in subjects with EGJOO. Our study suggests that instead of calculating the median IRP, IRP could be calculated from the average between the first and the last swallow. Further studies are needed to confirm our findings. These studies should involve different GI function units and different types of HREM equipment.

\section{Financial support: None.}

\section{Conflicts of interest: None.}

Author contributions: Abbinaya Elangovan: data extraction, data analysis, and manuscript writing; Fahmi Shibli: study design and critical review of the manuscript; and Ronnie Fass: conception and design, interpretation of the data, critical revision of the article, and final approval of the article.

\section{References}

1. Fox MR, Bredenoord AJ. Oesophageal high-resolution manometry: moving from research into clinical practice. Gut 2008;57:405-423.

2. Zerbib F, Omari T. Oesophageal dysphagia: manifestations and diagnosis. Nat Rev Gastroenterol Hepatol 2015;12:322-331.

3. Kahrilas PJ, Bredenoord AJ, Fox M, et al. The Chicago classification of esophageal motility disorders, v3.0. Neurogastroenterol Motil 2015;27:160-174.

4. Yadlapati R. High-resolution esophageal manometry: interpretation in clinical practice. Curr Opin Gastroenterol 2017;33:301-309.

5. Schlottmann F, Herbella FA, Patti MG. Understanding the Chicago classification: from tracings to patients. J Neurogastroenterol Motil 2017;23:487-494.

6. Perinetti G. StaTips Part IV: selection, interpretation and reporting of the intraclass correlation coefficient. South Eur J Orthod Dentofac Res 2018;5:3-5.

7. Bredenoord AJ, Fox M, Kahrilas PJ, Pandolfino JE, Schwizer W, Smout AJ. Chicago classification criteria of esophageal motility disorders defined in high resolution esophageal pressure topography. Neurogastroenterol Motil 2012;24(suppl 1):57-65.

8. Herregods TVK, van Hoeij FB, Bredenoord AJ, Smout AJPM. Subtle lower esophageal sphincter relaxation abnormalities in patients with unexplained esophageal dysphagia. Neurogastroenterol Motil 2018;30:e13188.

9. Zhang X, Xiang X, Tu L, Xie X, Hou X. Esophageal motility in the supine and upright positions for liquid and solid swallows through highresolution manometry. J Neurogastroenterol Motil 2013;19:467-472.

10. Xiao Y, Read A, Nicodème F, Roman S, Kahrilas PJ, Pandolfino JE. The effect of a sitting vs supine posture on normative esophageal pressure topography metrics and Chicago classification diagnosis of esophageal motility disorders. Neurogastroenterol Motil 2012;24:e509-e516.

11. Roman S, Damon H, Pellissier PE, Mion F. Does body position modify the results of oesophageal high resolution manometry? Neurogastroenterol Motil 2010;22:271-275.

12. Sweis R, Anggiansah A, Wong T, Kaufman E, Obrecht S, Fox M. Normative values and inter-observer agreement for liquid and solid bolus swallows in upright and supine positions as assessed by esophageal highresolution manometry. Neurogastroenterol Motil 2011;23:509-e198.

13. Ciriza-de-Los-Ríos C, Canga-Rodríguez-Valcárcel F, Lora-Pablos D, De-La-Cruz-Bértolo J, Castel-de-Lucas I, Castellano-Tortajada G. How the body position can influence high-resolution manometry results in the study of esophageal dysphagia and gastroesophageal reflux disease. J Neurogastroenterol Motil 2015;21:370-379.

14. Triggs JR, Carlson DA, Beveridge C, et al. Upright integrated relaxation pressure facilitates characterization of esophagogastric junction outflow obstruction. Clin Gastroenterol Hepatol 2019;17:2218-2226, e2.

15. Xiang X, Wang A, Tu L, et al. The differences in the esophageal motility between liquid and solid bolus swallows: a multicenter high-resolution manometry study in Chinese asymptomatic volunteers. Neurogastroenterol Motil 2019;31:e13574. 